\title{
Cemetery Mapping and Digital Data Analysis: A Case Study in Minnesota, USA
}

\author{
Maureen L. Schmidt ${ }^{1}$, Fei Yuan ${ }^{1}$, and Woo Jang ${ }^{1}$ \\ ${ }^{1}$ Department of Geography, Minnesota State University, Mankato, Minnesota, USA \\ Correspondence: Fei Yuan, Department of Geography, Minnesota State University, Mankato, Minnesota, USA. \\ Tel: 507-389-2376 E-mail: fei.yuan@mnsu.edu
}

Received: May 15, 2020

doi:10.5539/jgg.v12n2p40

\author{
Accepted: July 3, $2020 \quad$ Online Published: August 31, 2020 \\ URL: http://dx.doi.org/10.5539/jgg.v12n2p40
}

\begin{abstract}
This study examines how geospatial technologies can be used in the aid of local-level cemetery management with limited resources using a case study in Woodland Hills Memorial Park Cemetery, Minnesota, USA. The hard-copy records in a handwritten ledger were manually transferred into an Excel table. The spatial data of the gravesites were collected using a Trimble Geo 7X unit with a Zephyr antenna and a Laser Rangefinder sensor over the summer of 2017. A geodatabase was constructed by joining the Excel table with the GPS data in GIS. A procedure was also developed to map the spatial distributions of plots and analyze the demographic data. It was demonstrated that a very high locational accuracy could be achieved based on carefully designed GPS data collection strategies. In addition, the data analysis results revealed that there were 12,190 plots in total, approximately half of which were still available for purchase. Among the 5,906 inhabitants buried at the Woodland Hills, many were ethnically German and Scandinavian, of whom 9.7\% were veterans and nearly half were from the Greatest Generation (born between 1901 and 1927). The birth, death, and age distributions are significantly different between the nonveteran and veteran groups. Clustered patterns were identified for the filled plots and all the Generation categories. Such results will be beneficial to local cemetery managers to plan for further development as well as to future historians or individuals interested in the local culture and history. The proposed methods can greatly facilitate local-level cemetery data collection, mapping, query, and analysis.
\end{abstract}

Keywords: GPS, Geodatabase, GIS, Spatial Analysis, Genealogical Analysis, Cemetery Management

\section{Introduction}

Cemeteries play an important role in the community. As a vital place for remembrance and mourning, they need to be properly planned for and maintained. Traditionally, cemetery property maps that show the boundaries, sections, subdivisions, lots, and grave spaces were sketched by hand or cartographic software in a fixed scale. Paper records were usually kept. The related attribute data were also typically recorded in paper books or spreadsheets and were updated manually. This traditional method of cemetery mapping and record management is tedious, time-consuming, and cost-ineffective. As the hard-copy property maps and attribute data are not connected, it is also difficult to update and manage the records. In addition, paper maps and files are hard to store and carry and can easily be misplaced, ripped, or stolen. Paper materials deteriorate over time and are susceptible to fires and water-related disasters. Pencil markings fade over time and are easily smudged. Furthermore, the actual information contained within these records varies and the lack of standardization means that vital information may not be recorded (Bennett \& Davies, 2015; Schmidt, 2018).

Consequently, a recent trend is to use Geographic Information System (GIS) as a tool to either recreate these records digitally or ensure that modern records are taken appropriately (Ayers, 2006; Gonzalez-Tennant, 2009; Güney \& Celik, 2003; Quesada, Baena, \& Blasco, 1994). At national-level, the Historic American Landscape Survey/Cultural Resources GIS (CRGIS) within the National Park Service (NPS), working together with the United States Department of Veterans Affairs' National Cemetery Administration, has used GIS and GPS on inventory cultural resources from battlefields to national cemeteries (Stein, 2006; NPS (n.d.)). Likewise, Arlington National Cemetery with 400,000 gravesites has gone through the digital transformation recently (Montalbano, 2012). Nevertheless, these national-level projects were focused on data collection and storing, not on cemetery data analysis. 
Scientists have called for turning genealogical analysis onto GIS since numerous types of data can be represented in GIS projects (Shular, 2009). However, despite their well-recognized advantages, geospatial technologies have not been rapidly and consistently deployed in cultural resource management, especially at the local-level cemetery management, mainly because of a lack of funding, technological personnel and skills, and other infrastructure, as well as historical and logistical issues (Montalbano, 2012; Sanjuán, \& Wheatley, 1999). Besides, demographic and genealogical research focused on cultural and historical analysis using GIS data is still very limited. There is a lack of systematic framework and procedure for digital cemetery mapping and data analysis, especially for a local-scale cemetery with limited resources.

In this context, this study aimed to address the following key research questions: Can we digitally transform traditional cemetery data using GIS with limited resources so local cemetery managers can manage cemeteries more efficiently? How to achieve high locational accuracy using Global Positioning System (GPS) in order to meet the requirement of a cemetery mapping project? Based on the digital geodatabase created in the study, what kind of demographic and genealogical analysis can be conducted effectively? Can any spatial distribution patterns or trends in the collected data be identified using spatial analysis (e.g. Moran's I)?

Specific objectives were to (1) collect highly accurate gravesites locational data using GPS and convert the hardcopy attribute records of the cemetery into a digital table; (2) build a geodatabase for the Woodland Hills that can be queried by attributes and/or spatial locations in a GIS framework; (3) demonstrate how to analyze the collected spatial and attribute data using spatial analysis and statistical methods; and (4) determine what characteristics, spatial patterns, and trends the data collected (e.g. filled vs empty plots, veteran vs non-veteran, generations, etc.) displays, so the information can be made readily available to the cemetery managers, users, and researchers.

\section{Methods}

\subsection{Study Site}

The study site is the Woodland Hills Memorial Park Cemetery in Mankato, Minnesota. Established in 1938, the cemetery was formerly known as Grandview Memorial Park. It is located on top of a hill, southwest of Mankato on 1605 Woodland Ave. Bordered by residential neighborhoods to the north and west, it overlooks the Blue Earth River to its northwest, and the Rasmussen Woods to the east (Figure 1). It is the only memorial park in the Mankato area. This cemetery differs from traditional ones, as bronze plaques are mounted at ground level (instead of erecting headstones) on a granite base to blend with the lawns in order to maintain park view and facilitate maintenance. Clients get full ownership of their lots in a memorial park, as opposed to the limited burial rights of traditional cemeteries. The plotted portions of the Woodland Hills Memorial Park, the funeral home, outbuildings, parking lots, and roads have a total area of approximately 22-acre. Woodland Hills Memorial Park Cemetery has four gardens: Christus, Devotion, Tower, and Peace. There is also a mixture of trees, sculptures, and memorial benches in the gardens, forming a tranquil and beautiful place for families and friends of the bereaved to reminisce. In the past, to find information about a specific grave, one must manually search through the hardcover book of records while referring to the physical maps in an effort to examine the gravesites in any spatial capacity. This cemetery provides an ideal case study site for digitally transforming traditional cemetery management using geospatial technologies.

\subsection{Tabular Data Inputs}

Each of the four gardens in the Woodland Hills Memorial Park Cemetery is divided into lots that are further split to four sections, labeled A - D. Section A is in the upper left corner, section B in the lower left, section C in the upper right, and section $\mathrm{D}$ in the bottom right of the lot marker. Each section has four plots $(1-4)$, or grave spaces. Therefore, there are 16 grave spaces for each lot in total. In order to convert the handwritten records to digital tables, pictures were taken for each page of the record book, which were then used as a reference for entering the data in Excel. The lot number, section code (A-D), and plot space number (1-4) were recorded and concatenated to form a unique identification number for each gravesite. In addition to the name of the lot owners, the deed number, and any information regarding the type of marker was recorded when available.

\subsection{Data Dictionary Creation}

Before the GPS data collection, a field survey was performed in the study site to become familiar with the landscape and determine what type of data could be collected. In the meantime, the cemetery managers were consulted to determine what information would be most useful for their records, and what type of structure would be best for their use. Next, a data dictionary that serves as a template for entering information in a GPS unit was created in the Pathfinder Office Data Dictionary Editor to streamline the process of data collection. Data dictionaries can improve data quality and integrity, reduce data redundancy, and improve the accuracy of the 
collected data by standardizing the format and type of input variables. Another advantage is they store both attribute information and locational information of each feature together.

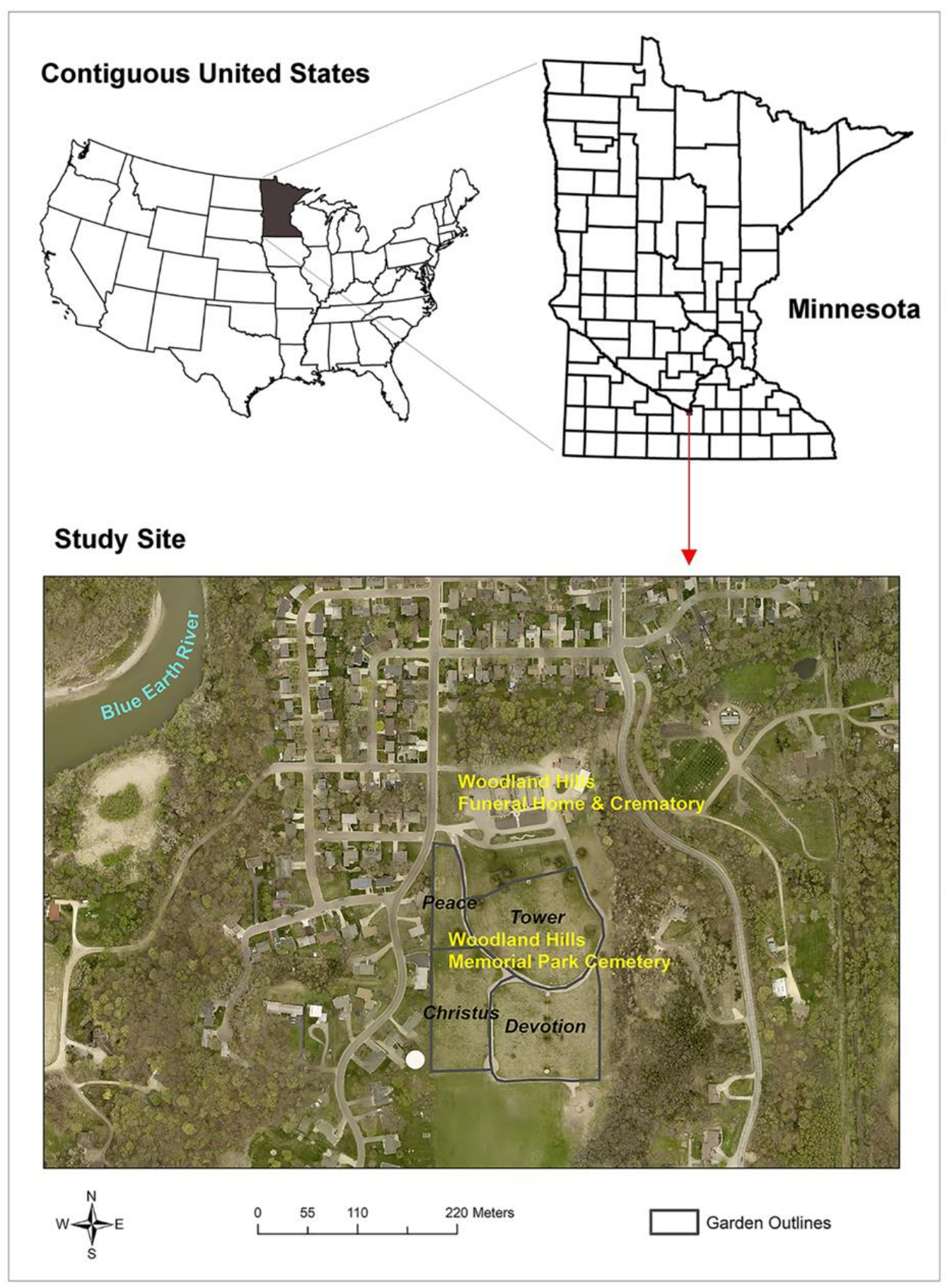

Figure 1. Woodland Hills Memorial Park Cemetery and surrounding areas in high-spatial resolution $(7.62 \mathrm{~cm}$ or 3 in) digital aerial imagery

In this study, numeric attributes were used to store data such as the dates of the interred or the lot and plot numbers associated with each grave space whereas text variables were used to note the names of the interred. Menu attributes provide the user the option to choose from a list of drop-down options, such as the type of veteran, if there was an epitaph on the plaque, whether there was an urn present beside the grave, and if the marker stood alone or was connected to another (Schmidt, 2018). The Lot, Empty Lot, and Plot point features were created in the data dictionary. The Lot and Empty Lot features had a single numeric attribute for noting the number of each 
lot marker while the Plot feature had attributes for the lot, section, plot, the date of birth (DoB), and date of death (DoD), as well as first, middle, and last names.

\subsection{GPS Data Collection and Processing}

The finalized data dictionary was exported to the handheld GPS device and used in the TerraSync software when collecting data using the GPS. The next step is to determine the accuracy requirement of the study. Due to the proximity of the gravesites $(2.5 \mathrm{ft}$ or $76 \mathrm{~cm})$ to each other, high accuracy is required for this study. Therefore, the accuracy threshold was set as $20 \mathrm{~cm}$, to prevent overlap between the plot points that may incorrectly indicate the order or location of the gravesites. The accuracy of GPS data is affected by four factors: (a) GPS satellites, such as orbital and clock errors, (b) GPS receiver uncertainties related to clock error, multipath error, system noise, antenna phase center variations, (c) atmospheric refraction in ionospheric layer and tropospheric layer, and (d) satellite geometric effect, such as dilution of precision (El-Rabbany, 2006; Kim et al., 2017; Lejeune \& Warnant, 2008; Li et al., 2015; Marathe, Daneshmand, \& Lachapelle 2016; Martinez, Martinez, \& Garcia-Cerezo, 2000; Weng et al., 2014).

To satisfy the accuracy requirement for the project, Trimble Geo 7X GPS units with high acquisition accuracy (up to $1 \mathrm{~cm}$ ) and large touchscreen were used. However, even though the Trimble Geo 7X GPS units could theoretically provide up to $1 \mathrm{~cm}$ accuracy, a much lower accuracy of 1-2 $\mathrm{m}$ would be obtained in some places due to the presence of trees in the cemetery and other factors aforementioned. To meet the $20 \mathrm{~cm}$ accuracy requirement, a Zephyr Model 3 antenna sensor was used to improve the vertical accuracy and a Laser Rangefinder (LRF) sensor was attached to the GPS unit to accurately collect data in areas where obstacles such as trees blocked satellite signals. In addition, the data was collected in the summer of 2017 in sunny or partly cloudy days, primarily from 10 am to noon and $1 \mathrm{pm}$ to $3 \mathrm{pm}$ when the number and angles of the satellite are the most ideal based on the Trimble Planning software, which achieves better accuracy and works efficiency in the field. Each of the four gardens was completed in the order of lot number, with individual plots collected by the lot. On average, each garden took three weeks to complete the data collection. Finally, the collected GPS point feature layers were exported from Geo 7X to Pathfinder Office. The GPS locations in those feature layers were further improved by conducting a differential correction in the Pathfinder Office before they were exported into an ESRI geodatabase. The records from the Excel tables were then joined with these point features in the geodatabase using the unique ID for each grave that was created by combining the lot, section, and plot numbers.

\subsection{Data Analysis}

The spatial autocorrelation based on feature locations of the collected data was measured using the Global Moran's I statistic in ArcGIS. Moran's I is produced by standardizing the spatial auto-covariance by the variance using a measure of the connectivity of the data as shown in Equation 1. Resultant Moran's I values range from approximately -1 (high negative spatial autocorrelation) to 1 (high positive spatial autocorrelation) (Wong and Lee, 2005).

$$
\mathrm{I}=\frac{n \sum_{i} \sum_{j} W_{i j}\left(X_{i}-\bar{X}\right)\left(X_{j}-\bar{X}\right)}{\left(\sum_{i} \sum_{j} W_{i j}\right) \sum_{i}\left(X_{i}-\bar{X}\right)^{2}}
$$

Where $\mathrm{n}$ is the total number of observations, $\mathrm{W}_{\mathrm{ij}}$ is the distance between points $\mathrm{i}$ and $\mathrm{j}$; $\mathrm{x}_{\mathrm{i}}$ represents the variable value at the location $i$, and $x_{j}$ is the variable value at location $j$.

The expected Moran's I value was determined by Equation 2, should the data be randomly distributed. As the Moran's I index is the process of proving the null hypothesis of random distribution wrong, the observed value should be different from the expected value found in Equation 2. If the observed value is greater than the expected value, the data has a positive spatial autocorrelation (clustered pattern), and the converse is true for dispersed/uniform pattern. The Moran's I method also calculates a z-score (Equation 3) and the corresponding pvalue that indicates the statistical significance (Lee and $\mathrm{Li}, 2017$ ).

$$
E[\mathrm{I}]=\frac{-1}{n-1}
$$




$$
Z_{i}=\frac{I-E[I]}{\sqrt{\left(E\left[I^{2}\right]-E[I]^{2}\right)}}
$$

The collected attribute data were also analyzed to compute the total and available plots for each garden. The empty spaces were further broken down by section numbers (A-D), plot numbers (1-4) and the unique plot place of each section. Next, the lifespan of veteran and non-veteran were compared. Specifically, based on the Year of Birth $(\mathrm{YoB})$ and Year of Death (YoD) information in the geodatabase, ages of the inhabitants buried at the cometary were computed and split into non-veteran and veteran two groups. In particular, the normality of the data was tested using both the Lilliefors-corrected Kolmogorov-Smirnov (K-S) and Shapiro-Wilk tests in SPSS 24.0 (SPSS Inc., Chicago, Illinois, USA). Both tests serve the same purpose. The Shapiro-Wilk test quantifies the similarity between the observed and normal distributions by calculating the percentage of the sample that overlaps with the normal distribution while the K-S compares the observed versus the expected cumulative relative frequencies (Shapiro \& Wilk, 1965; SPSS (n.d.)). The Shapiro-Wilk test has more power for a given significance than the K$\mathrm{S}$ test but is more appropriate for small sample sizes (Razali \& Wah, 2011). The Lilliefors-corrected K-S test is an improvement on K-S test by correcting the K-S for small values at the tails of probability distributions (Lilliefors, 1967). Next, Because the data were not normally distributed based on the results of the Lilliefors-corrected K-S and Shapiro-Wilk tests, the nonparametric Mann-Whitney U test was adopted to determine whether the veteran and non-veteran groups having the same YoB, YoD, and Age distributions. The Mann-Whitney U test can test whether two samples have the same shape by comparing the medians of the two groups based on a test statistic $\mathrm{U}$ (Mann \& Whitney, 1947), which is the smaller of $U_{1}$ (Equation 4) and $U_{2}$ (Equation 5).

$$
\begin{aligned}
& U_{1}=\mathrm{n}_{1} \mathrm{n}_{2}+\frac{\mathrm{n}_{1}\left(\mathrm{n}_{1}+1\right)}{2}-R_{1} \\
& U_{2}=\mathrm{n}_{1} \mathrm{n}_{2}+\frac{\mathrm{n}_{2}\left(\mathrm{n}_{2}+1\right)}{2}-R_{2}
\end{aligned}
$$

Where $\mathrm{n}_{1}$ and $\mathrm{n}_{2}$ are the sample sizes of groups 1 (veteran) and 2 (non-veteran) respectively, $\mathrm{R}_{1}=$ sum of the ranks for group 1 , and $\mathrm{R}_{2}=$ sum of the ranks for group 2 .

In addition, a frequency analysis was performed to determine the five most common first and last names using the information presented on the plaques. The total number of veterans buried at the cemetery was categorized. Finally, those buried at the cemetery were divided into seven generation categories based on their year of birth (Table 1)

\begin{tabular}{|c|c|c|}
\hline Generations & Birth Years & Descriptions \\
\hline Lost Generation & Pre-1901 & Prior to the turn of the century. \\
\hline $\begin{array}{l}\text { Greatest } \\
\text { Generation }\end{array}$ & 1901 to 1927 & Characterized by young adults' involvement in world wars. \\
\hline Silent Generation & 1928 to 1945 & $\begin{array}{l}\text { Comparatively small because of the financial insecurity of the } \\
\text { 1930s and WWII in the early 1940s. It includes most of those who } \\
\text { fought during the Korea War. }\end{array}$ \\
\hline Baby Boomers & 1946 to 1964 & $\begin{array}{l}\text { Many grew up during a period of increasing affluence post- } \\
\text { WWII. }\end{array}$ \\
\hline Generation X & 1965 to 1980 & $\begin{array}{l}\text { Children during a time of shifting societal values due to increased } \\
\text { maternal participation in the workforce and lack of childcare } \\
\text { options outside the home. }\end{array}$ \\
\hline Millennials & 1981 to 2000 & Saw the next turn of the century from 1981 to 2000 . \\
\hline Generation Z & After 2001 & Accounted for anyone who was born after 2001. \\
\hline
\end{tabular}
for cohort/generational analysis.

Table 1. Description of the seven-generation categories based on their year of birth. 


\section{Results}

\subsection{The WHMP Geodatabase, Lot Distributions, and Plot Statistics}

The WHMP Geodatabase includes four major feature classes: Lots, Plots, Empty (Plots), and Family_Markers, in addition to the roads and statues layers. As mentioned before, the spatial locational information and attribute data of the gravesites were linked using grave identification based on the lot, section, and plot numbers. The attribute table of the Plot feature layer include following attributes: Lot, Section, Plot, FirstName, MiddleName, LastName, DoB, DoD, Veteran, Epitaph, Urn, and Marker, as shown in Table 2.

Table 2. Example of the Plot feature attribute table*.

\begin{tabular}{|c|c|c|c|c|c|c|c|c|c|c|c|}
\hline $\begin{array}{l}\text { Lot } \\
\#\end{array}$ & $\begin{array}{l}\text { Sec. } \\
\#\end{array}$ & $\begin{array}{l}\mathrm{Pl} \\
. \#\end{array}$ & $\begin{array}{l}\text { First } \\
\text { Name }\end{array}$ & $\begin{array}{l}\text { M. } \\
\text { int. }\end{array}$ & $\begin{array}{l}\text { Last } \\
\text { Name }\end{array}$ & DoB & DoD & $\begin{array}{l}\text { Vet- } \\
\text { eran }\end{array}$ & $\begin{array}{l}\text { Epi- } \\
\text { taph }\end{array}$ & Urn & Marker \\
\hline 73 & A & 2 & Jane1 & C. & Doe1 & $06 / 17 / 1949$ & & No & No & No & Mult. \\
\hline 73 & A & 1 & John1 & M. & Doe1 & $11 / 02 / 1948$ & $08 / 22 / 2003$ & No & No & No & Mult. \\
\hline 73 & B & 1 & John2 & D. & Doe2 & 1929 & 2015 & No & No & No & Mult. \\
\hline 73 & B & 2 & Jane2 & F. & Doe2 & 1933 & & No & No & No & Mult. \\
\hline 73 & B & 3 & John3 & W. & Doe3 & 03/13/1929 & $01 / 08 / 2016$ & Korean & Yes & No & Single \\
\hline 73 & B & 4 & Jane3 & $\mathrm{J}$ & Doe3 & 05/14/1935 & & No & Yes & No & No \\
\hline 73 & $\mathrm{C}$ & 1 & John4 & J. & Doe4 & 1930 & 2015 & No & No & No & Mult. \\
\hline 73 & $\mathrm{C}$ & 2 & Jane4 & L. & Doe4 & 1935 & 2010 & No & No & No & Mult. \\
\hline 73 & D & 1 & John5 & W. & Doe4 & $02 / 29 / 1960$ & $10 / 29 / 2016$ & No & Yes & No & Single \\
\hline
\end{tabular}

* The true first and last names were intentionally concealed in this table to protect the privacy of the inhabitants buried in the cemetery.

Among the four gardens, Devotion is the largest, followed by the Tower, and then Christus, while Peace is the smallest. There were 12,190 plots in the cemetery, with 6,500 available plots of land for purchase (Table 3). Devotion also had the lowest vacant rate $(43.06 \%)$ whereas the opposite was true for Peace $(71.47 \%)$. The measured elevations of the plots range from $275.7 \mathrm{~m}$ to $304.5 \mathrm{~m}$. There were 140 family markers and the majority of them located in the Devotion and Christus gardens, which have higher elevations than the Tower and Peace. While Woodland Hills sells all of their grave plots at the same rate, other cemeteries may take advantage of such practice of putting more value on filling up areas.

Table 3. Available Plots by Garden.

\begin{tabular}{cccccc}
\hline \multirow{2}{*}{ Garden Name } & \multicolumn{2}{c}{ Plots by Garden } & \multicolumn{2}{c}{ Available Plots by Garden } & \multirow{2}{*}{$\begin{array}{c}\text { Vacant } \\
\text { rate }\end{array}$} \\
\cline { 2 - 5 } & $\#$ & $\%$ & $\#$ & $\%$ & $52.84 \%$ \\
Christus & 3,261 & $26.75 \%$ & 1,723 & $26.51 \%$ & $43.06 \%$ \\
Devotion & 4,308 & $35.34 \%$ & 1,855 & $28.53 \%$ & $61.04 \%$ \\
Tower & 3,650 & $29.94 \%$ & 2,228 & $34.28 \%$ & $71.47 \%$ \\
Peace & 971 & $7.97 \%$ & 694 & $10.68 \%$ & - \\
\hline Total & 12,190 & $100.00 \%$ & 6,500 & $100.00 \%$ & \\
\hline
\end{tabular}

The distribution of grave plots throughout the cemetery is shown in Figure 2. It is apparent more empty graves were located along the edges of the garden. The result of spatial autocorrelation (Global Moran's I test) with a Zscore of 205.84 and P-value of 0.000 further confirmed the clustered pattern of the plots. 


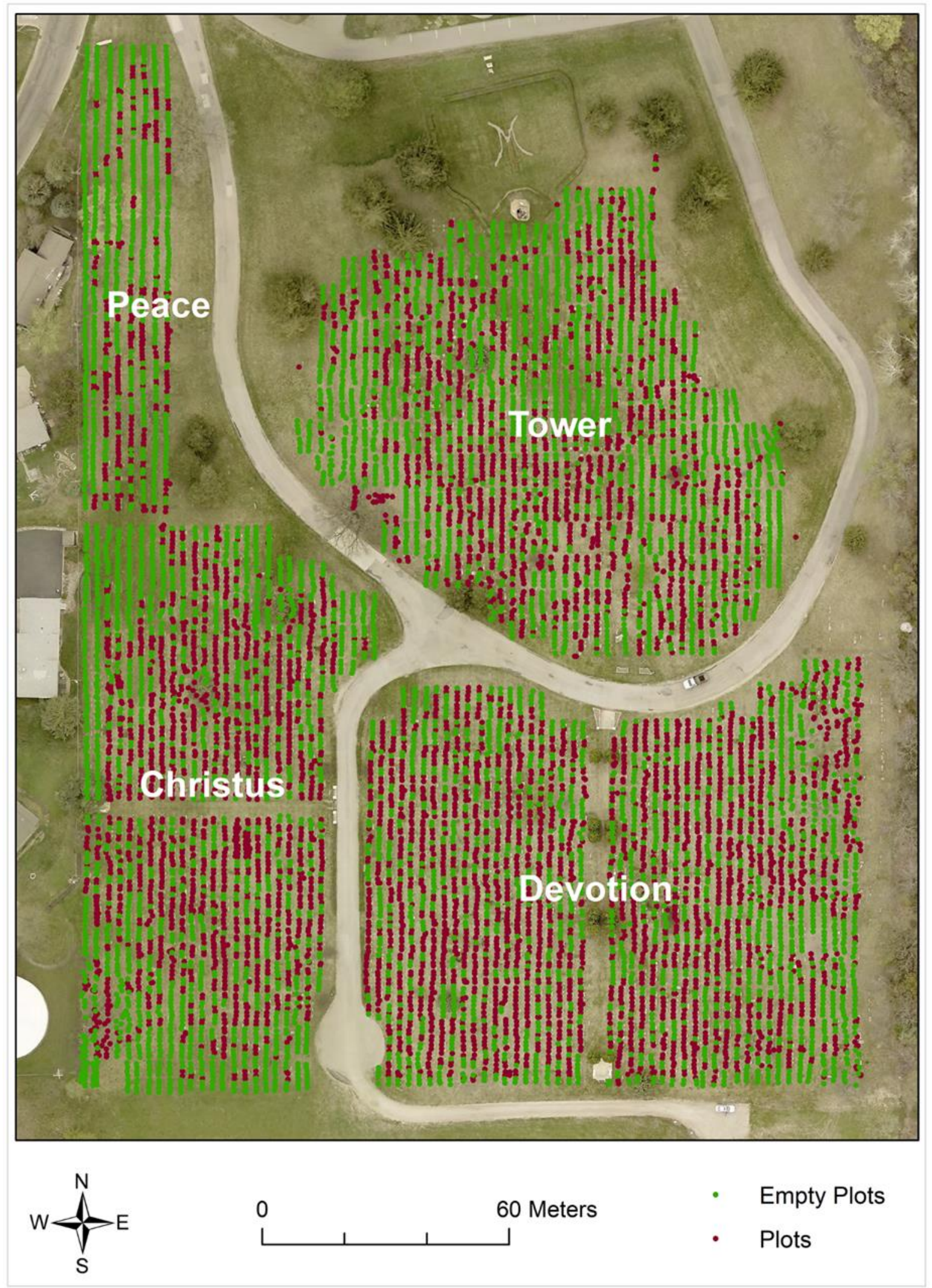

Figure 2. The distribution of plots throughout the cemetery. 
Further analysis results indicated that the distribution of empty graves throughout each section (A-D) or each plot (1-4) was roughly even. Comparatively, Plot 1 and Plot 2 had slightly fewer available spaces, followed by Plot 3 , while Plot 4 had the most available spaces (Figure 3). Although it is unclear why there is a slight preference for Plots 1 and 2 spaces, this information will help cemetery managers push sales of plots 3 and 4 spaces.

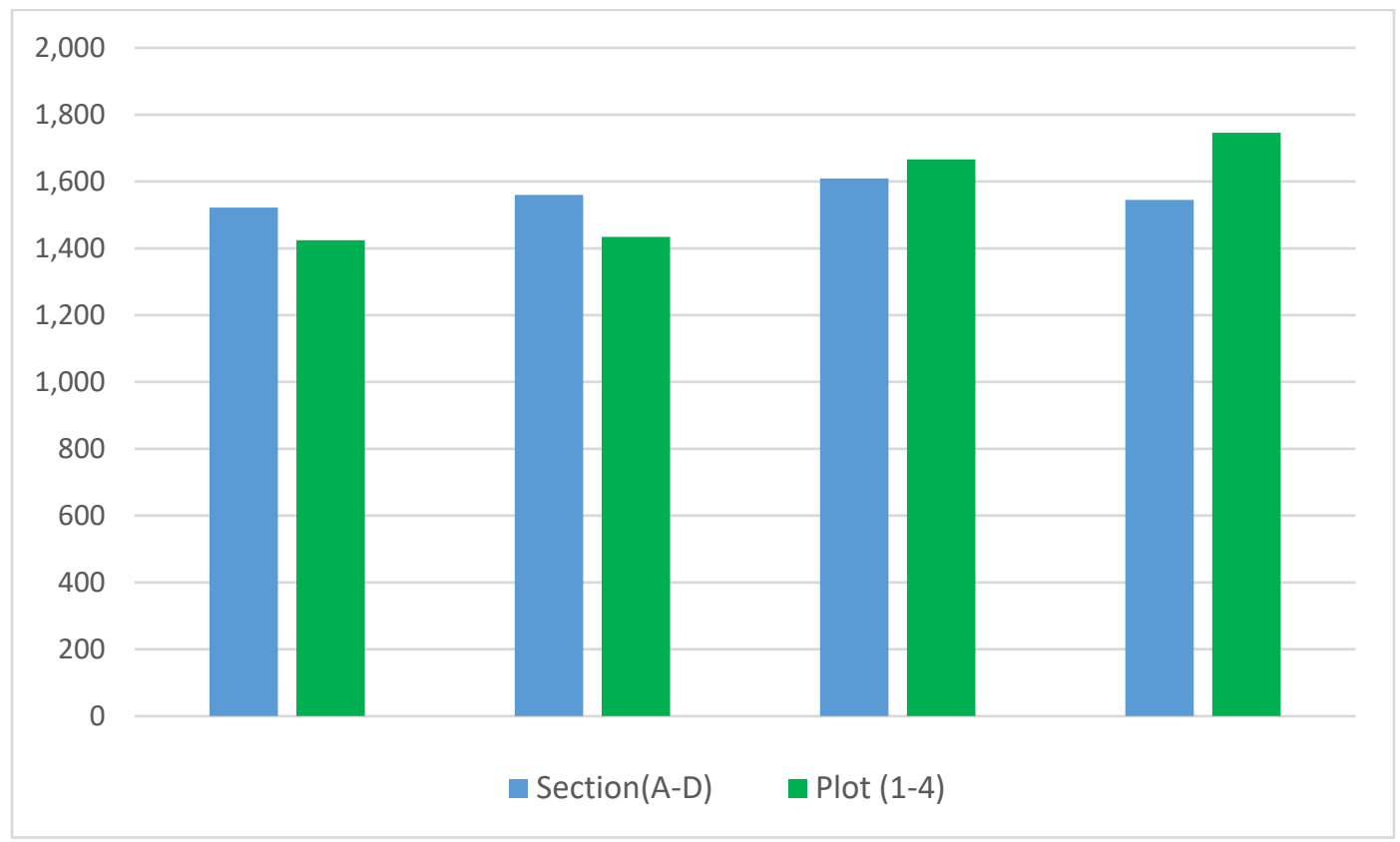

Figure 3. Number of Available Plots by Section or by Plot.

\subsection{Veteran vs Non-Veteran Comparison Results}

A total of 5,905 inhabitants were buried at Woodland Hills, among which veterans made up approximately $9.7 \%$ of the total. The majority of those soldiers $(42.4 \%)$ served in WWII, and a large number served in WWI (6.0\%), Korean (12.4\%), Vietnam (7.0\%) and other conflicts such as the Gulf Wars and from general service (32\%). Fewer veterans from WWI than the ones from WWII and the Korean War in the cemetery since the Woodland Hills Memorial Park Cemetery was established in 1938. The distribution of veteran and non-veteran plots indicated a random pattern (Figure 4). This is further confirmed by the global Moran's I test based on a z-score of 0.087 and a p-value of 0.93 .

Based on the Dates of Birth and Death of the inhabitants that were correctly recorded (4,988 out of the total 5,905), the lifespan statistics were calculated (Table 4). Results reveal that the average age buried at the cemetery was 72 years with a standard deviation of 20.08 years whereas the median age was 77 years. Compared to non-veteran, the mean and median lifespan of the veterans was 71 and 74 years, respectively. On average, veterans were borne six years after the nonveterans. Data exploratory analysis shows the histogram of YoB was slightly skewed to the left side while those of $\mathrm{YoD}$ and Age were highly skewed to the right side. The results of normality tests $(\mathrm{P}<0.05)$ further confirmed the significant non-normal distributions of these variables (Table 5). 


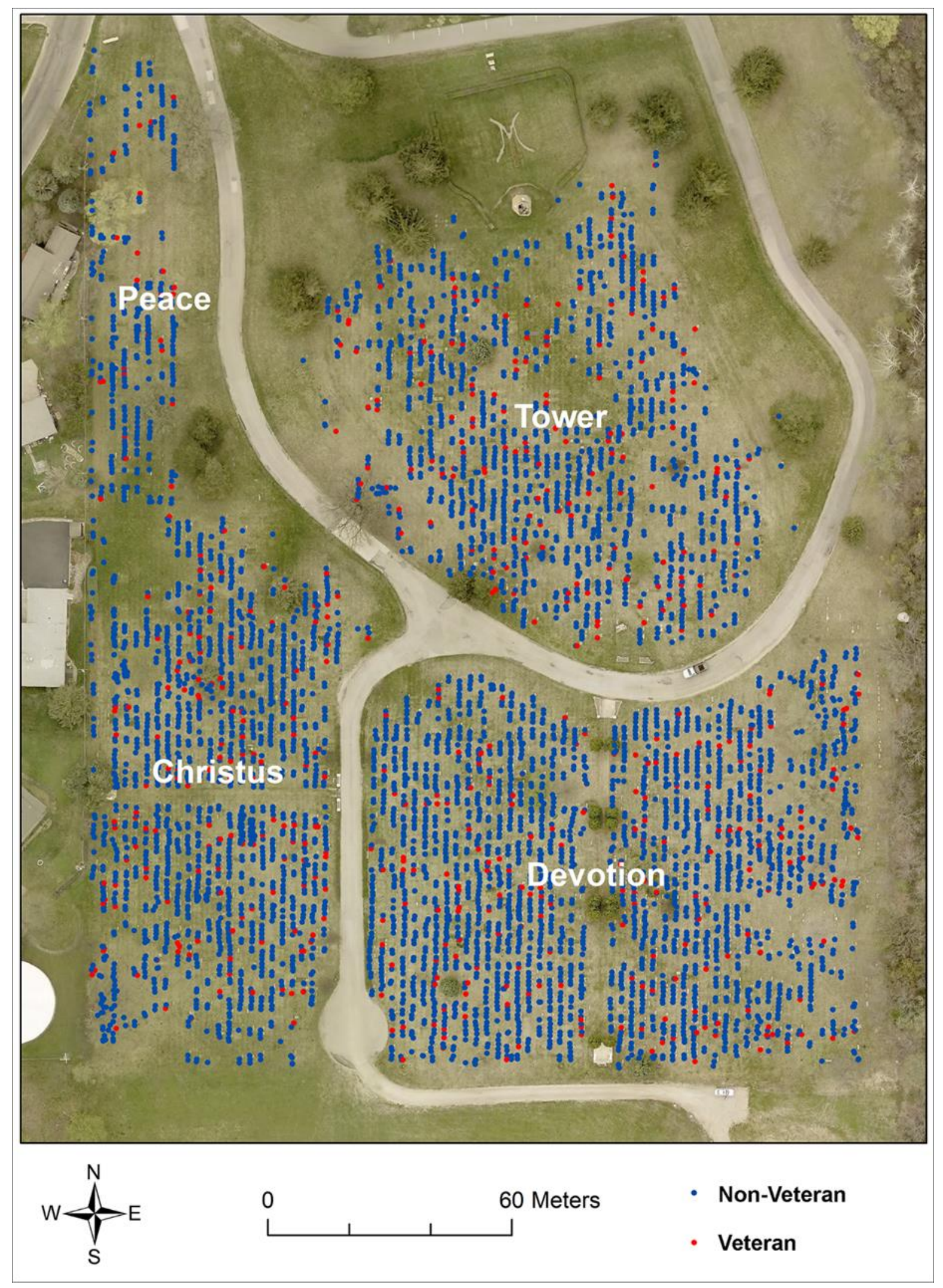

Figure 4. The distribution of veteran and non-veteran plots. 
Table 4. Lifespan statistics of the inhabitants buried at the cemetery.

\begin{tabular}{cccccccccccc}
\hline \multirow{5}{*}{ Veteran } & Var. & Size & Mean & $\begin{array}{c}\text { Std. } \\
\text { Dev }\end{array}$ & $\begin{array}{c}\text { Std. } \\
\text { Err. }\end{array}$ & Range & Max & Min & Median & $25 \%$ & $75 \%$ \\
& YoB & 566 & 1923 & 15.39 & 0.65 & 112 & 1989 & 1877 & 1923 & 1916 & 1931 \\
& YoD & 566 & 1994 & 16.25 & 0.68 & 76 & 2017 & 1941 & 1998 & 1981 & 2008 \\
& Age & 566 & 71 & 16.15 & 0.68 & 83 & 102 & 19 & 74 & 60 & 83 \\
\hline \multirow{3}{*}{ Non- } & YoB & 4422 & 1916 & 22.36 & 0.34 & 167 & 2013 & 1846 & 1915 & 1902 & 1927 \\
Veteran & YoD & 4422 & 1988 & 17.84 & 0.27 & 110 & 2017 & 1907 & 1990 & 1976 & 2003 \\
& Age & 4422 & 72 & 20.45 & 0.31 & 110 & 110 & 0 & 77 & 65 & 86 \\
\hline \multirow{4}{*}{ All } & YoB & 4988 & 1917 & 21.83 & 0.31 & 167 & 2013 & 1846 & 1916 & 1903 & 1928 \\
& YoD & 4988 & 1989 & 17.77 & 0.25 & 110 & 2017 & 1907 & 1991 & 1976 & 2004 \\
& Age & 4988 & 72 & 20.08 & 0.28 & 110 & 110 & 0 & 77 & 65 & 85 \\
\hline
\end{tabular}

Table 5. Results of Normality Tests.

\begin{tabular}{|c|c|c|c|c|c|c|}
\hline & \multicolumn{3}{|c|}{ Lilliefors-Corrected Kolmogorov-Smirnov } & \multicolumn{2}{|c|}{ Shapiro-Wilk } & \multirow[b]{2}{*}{ Sig. } \\
\hline & Statistic & $\mathrm{df}$ & Sig. & Statistic & $\mathrm{df}$ & \\
\hline YoB & 0.068 & 4988 & 0.000 & 0.972 & 4988 & 0.000 \\
\hline YoD & 0.073 & 4988 & 0.000 & 0.965 & 4988 & 0.000 \\
\hline Age & 0.13 & 4988 & 0.000 & 0.859 & 4988 & 0.000 \\
\hline
\end{tabular}

Therefore, the nonparametric Mann-Whitney Rank Sum test was used to test whether the veteran and non-veteran groups have the same distribution in terms of YoB, YoD, and Age. The Mean Rank values (Table 6) for both groups indicate statistically there is a greater percentage of veterans that are younger and have a shorter lifespan compared to those of the non-veterans. The significance values shown in Table 7 are less than 0.01 which indicates the distributions of YoB, YoD, and Age are significantly different between the Veteran and Non-veteran groups. However, it should be noted that the Woodland Hills Memorial Park Cemetery is a relatively small, newer cemetery and therefore such statistical and demographic findings need to be further validated using larger data sets.

Table 6. Ranks of the Mann-Whitney test for Veteran and Non-veteran groups.

\begin{tabular}{ccccc}
\hline Groups & & $\mathrm{N}$ & Mean Rank & Sum of Ranks \\
\hline YoB & Veteran & 566 & 3107.84 & 1759037.5 \\
& Non-veteran & 4422 & 2415.99 & 10683528.5 \\
YoD & Veteran & 566 & 2906.20 & 1644906.5 \\
& Non-veteran & 4422 & 2441.80 & 10797659.5 \\
\multirow{2}{*}{ Age } & Veteran & 566 & 2274.92 & 1287604.5 \\
& Non-veteran & 4422 & 2522.61 & 11154961.5 \\
\hline
\end{tabular}

Table 7. Mann-Whitney test statistics, the corresponding Z score, and significance value.

\begin{tabular}{cccc}
\hline & YoB & YoD & Age \\
\hline Mann-Whitney U & 904275.5 & 1018406.5 & 1127143.5 \\
Z & -10.763 & -7.225 & -3.854 \\
Asymp. Sig. (2-tailed) & $5.134 \mathrm{E}-27$ & $5.0199 \mathrm{E}-13$ & 0.000 \\
\hline
\end{tabular}

\subsection{Genealogical Analysis and Spatial Auto-correlation Analysis Results}

The ability to access demographic data is one of the important genealogical uses for managing cemetery using a digital geodatabase. Inferences can be made based on inhabitants' names even though most cemeteries do not store cultural and ethnic information (Schmidt, 2018). Table 8 shows the five most common first and last names presented on the plaques of the Woodland Hills Memory Park Cemetery. From the table we can see the most common first names appear are traditional English names that would be expected in a rural Midwestern town of the United States. The most common last names listed in the Table, such as Anderson, Nelson, and Peterson are 
common Scandinavian names while Johnson and Miller indicate the English/Scottish and German heritage of Minnesota. The results demonstrate it is possible to trace the ethnicity and immigration patterns through burial sites in a large-scale database.

Table 8 . The five most common first and last names presented in the cemetery.

\begin{tabular}{cccc}
\hline First Name & Frequency & Last Name & Frequency \\
\hline Robert & 100 & Johnson & 97 \\
John & 96 & Anderson & 68 \\
William & 83 & Nelson & 55 \\
Mary & 72 & Peterson & 46 \\
Donald & 60 & Miller & 42 \\
\hline
\end{tabular}

Lastly, generation distributions of the inhabitants buried at the cemetery are shown in Figure 5, which seems to follow what would be expected. Due to the age of the cemetery and no one buried at the cemetery prior to its creation, the Greatest Generation accounted for $45.61 \%$ of the inhabitants, followed by the Silent Generation (24.08\%), while Pre-1901 generation was only $18.78 \%$.

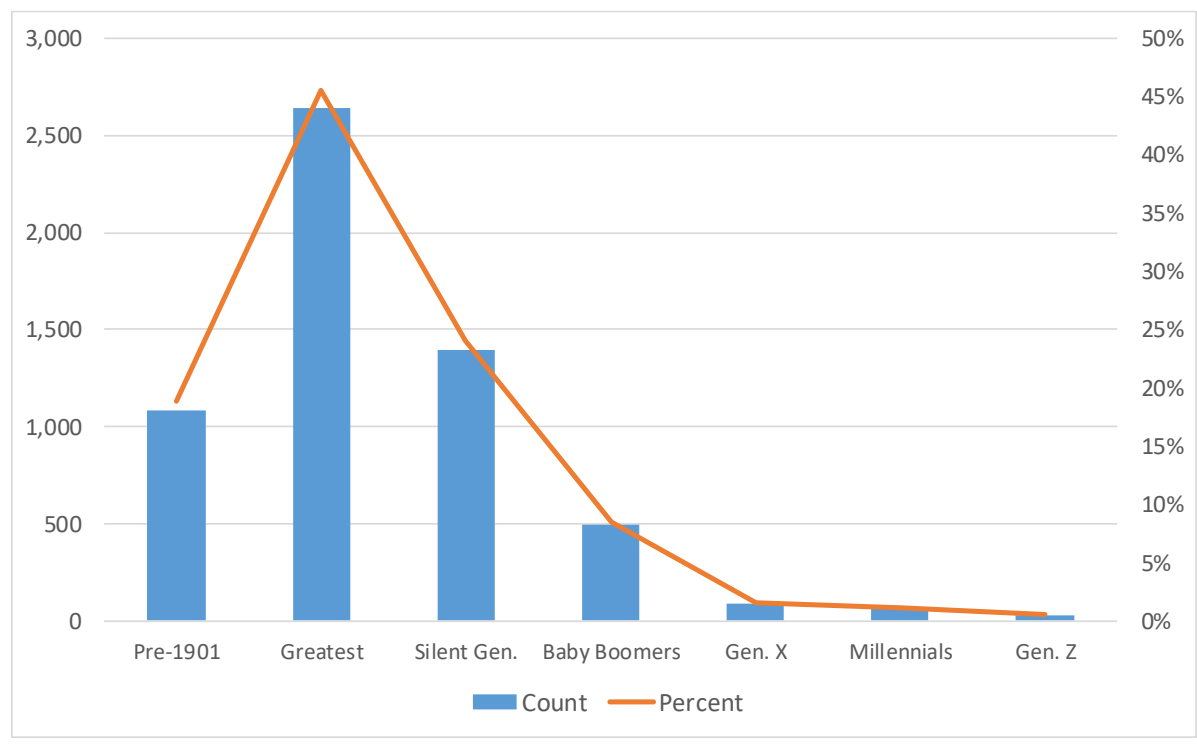

Figure 5. Generations of the inhabitants buried at the cemetery.

Based on the spatial auto-correlation analysis results (Table 9), all generations had Moran's I values revealing a clustered pattern with the P-Value less than 0.01 and the Z-score greater than 2.58 at a $99 \%$ confidence level. The Pre-1901 generation was the most clustered, with the highest Z-score of 42.787, while Generation X had the lowest value at 4.884. The spatial distribution of filled plots by generations is displayed in Figure 6. Clustered patterns can evidently be identified from this Figure, especially for the Pre-1901 generation.

Table 9. Moran's I Results of Generation

\begin{tabular}{l|ccc}
\hline GENERATION & MORAN'S I & Z-SCORE & P-VALUE \\
\hline PRE-1901 & 0.134 & 42.787 & 0.000 \\
GI GEN. & 0.058 & 18.574 & 0.000 \\
SILENT GEN. & 0.076 & 24.120 & 0.000 \\
BABY BOOMERS & 0.058 & 18.672 & 0.000 \\
GEN. X & 0.015 & 4.884 & 0.000 \\
MILLENNIALS & 0.020 & 6.430 & 0.000 \\
GEN. Z & 0.068 & 12.200 & 0.000 \\
\hline
\end{tabular}




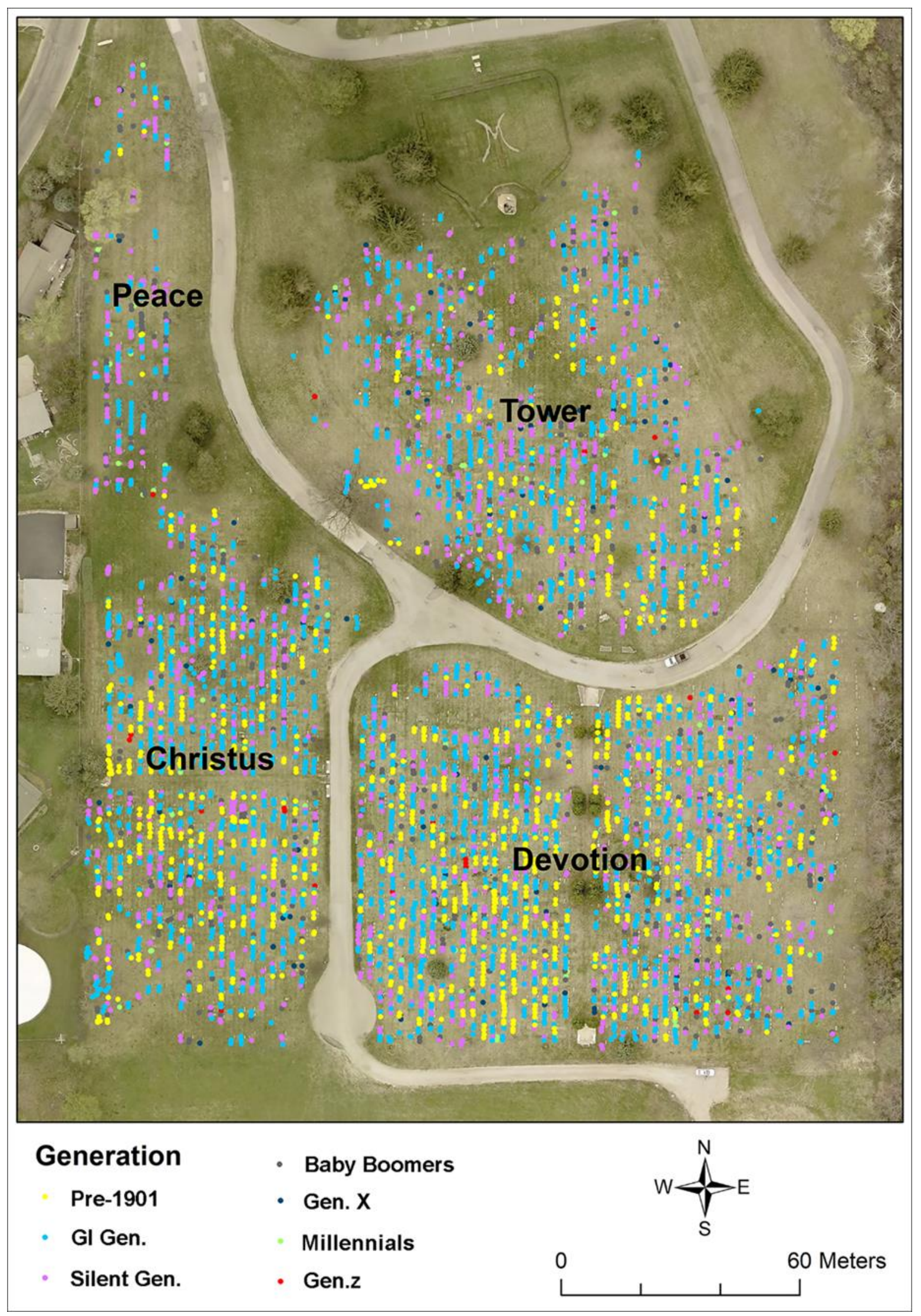

Figure 6. The distribution of filled plots by Generation. 


\section{Discussion}

\subsection{Challenges in Cemetery Management and the Implications}

Cemeteries are traditionally a mixture of private or religious organizations lacking a centralized structure. Most cemeteries are managed by private groups who need to be able to sustain themselves regarding maintenance fees and in the cost of land. Some graveyards are still owned and managed by religious organizations (Schmidt, 2018; Woodthorpe, 2011). Because no central governing factor or standards present in many countries, the local rules and regulations have been left to local governments to handle (Coutts, Basmajian, \& Chapin, 2011; Scholz, 2017; Hussein \& Rugg, 2003; Woodthorpe, 2011). While cemeteries were traditionally the purview of either a family or a religious organization such as a churchyard (Rugg, 2000), the modern need for cemeteries has expanded beyond such specific structures due to the upcoming deaths of a large elderly population. The industry as cemeteries must compete with other businesses to expand and overcome the local laws and regulations that are controlled by local governments. In addition, because cemeteries do not typically receive government funding, most are required to operate as businesses, including the Woodland Hills Memorial Park Cemetery. This means that gravesites are sold to individuals at a rate that needs to cover the operating costs and the future maintenance of the area, which include Landscaping cost, Property taxes, and Employees' salary as well as costs for services such as cremations, coffin sales, and wakes to customers (Faye \& Channac, 2017). Furthermore, they must maintain enough revenue to pay for the upkeep of the burial grounds, while allowing for the possibility of expansion into more land as the available spaces fill (Longoria, 2014). In addition to taking into account the cost of keeping up the graveyard when assigning prices to each gravesite and keeping the business operating, proper record-keeping practices need to be maintained to know the accurate locations and availabilities of each gravesite as well as the information of the interred (Faye \& Channac, 2017).

Basmajian and Coutts (2010) noted that modern urban areas are facing many challenges in keeping up with the necessary space and service requirements for disposing of the deceased. Open land is difficult to find in urban areas, especially in large metropolitan centres (Pattison, 1955). Not only limited by space availability, numerous prejudices and superstitions surrounding graveyards makes it difficult for cities to build new facilities (Davies \& Bennett, 2015; Davies \& Bennett, 2016). Many people have negative inferences with cemeteries and do not want to live next to them. However, society has seen a change in how people view cemeteries and other burial spaces over time (Johnson, 2018). Recent studies have proposed the concept of "Green urban cemeteries". This allows for the open space for these cemeteries, while also makes it possible for surrounding neighborhoods to benefit from the space that can no longer be used for development (Swensen, Nordh, \& Brendalsmo, 2016; Skår, Nordh, \& Swensen, 2018; Woodthorpe, 2011). Likewise, the Woodland Hills Memorial Park Cemetery, with bronze plaques mounted at ground level and a mixture of trees, sculptures, and memorial benches in the gardens, exemplifies a design of "Green urban cemeteries".

Another challenge with cemetery management is the lost or incomplete records for older cemeteries, especially the ones no longer have a caretaker or with poor management. Exhaustive processing must be done to restore the records and many of which will continue to have important data missing despite the best efforts of those involved (Matero \& Peters, 2003; Paine, 1992). Although the records of Woodland Hills Memorial Park Cemetery are wellpreserved, some of them still contain incomplete, missing, or wrong data. For example, for the total 5,905 inhabitants buried in the cemetery, only 4,988 have complete and correct records on the dates of birth and death. Therefore, it is important to standardize cemetery organization methods such as record keeping and updating, the type of information archived, and the structural and spatial layout of the grave plots. This can prevent issues with lost gravesites and unknown burials, allow cemetery managers to plan for further development efficiently, and create a historic and cultural record kept of those who had once lived in the area (Schmidt, 2018; Bennett \& Davies, 2015). Many previous cemetery studies have centered on how past human behaviours such as archaeology, anthropology, and history would have benefited from properly collected and maintained records (Matero \& Peters, 2003; Nielsen et al., 2015; Paine, 1992; Spurgeon, 2017). This case study presents an example on how to record cemetery data properly and combine them in a geodatabase as well as how to analyze the digital data quantitatively.

\subsection{Strengths and Weaknesses of the Proposed Methodology for Cemetery Management}

Due to a lack of funding, technological personnel and skills, and other infrastructure, as well as historical and logistical issues (Montalbano, 2012; Sanjuán \& Wheatley, 1999), to date, cemetery management has mainly based on traditional methods, especially for those local-scale cemeteries. Using Woodland Hills Memorial Park as an example, their property maps were sketched by hand on hard-copy paper maps to show users the locations of sections, lots, and spaces in the cemetery. Likewise, the associated attribute data such as lot number, deed number, lot owner, space, marker, etc., were recorded manually in paper-based lot books. 
This proposed data collection methods based on GPS and GIS technologies successfully helped create highly accurate geodatabase for Woodland Hills with limited time and funding $(\sim 5,000)$. Notably, most well designed GPS devices have a horizontal accuracy of 3 meters (Grimes, J. (n.d.)). As described in Section 2.4, in this study, if no additional data collection strategies were used, even the high-end Trimble Geo 7X GPS units could only achieve an accuracy of 1-2 $\mathrm{m}$ at some locations due to the presence of trees and the effects of other factors. However, a higher level of accuracy $(20 \mathrm{~cm})$ is required in this study due to the close proximity of gravesites to each other. To overcame this challenge, following strategies were adopted: (1) the Zephyr antenna and LRF sensor were used together with the Trimble Geo 7X GPS units to achieve higher locational accuracy; (2) data collection was only conducted on sunny or partly cloudy days, primarily from 10 am to noon and $1 \mathrm{pm}$ to $3 \mathrm{pm}$ when the satellite geometry was optimal, and the GPS error (e.g., atmospheric refraction) was minimized; and (3) the GNSS points have gone through differential corrections to ensure that the satellite signals were correctly received by the GPS unit. Based on these strategies, a very high accuracy $(2-3 \mathrm{~cm})$ was obtained in this project. It took approximately three months (4 hours per survey day) for two people to collect the spatial data for all the 12,190 plots in Woodland Hills, and another 2-3 months (4 hours per day) for the major analyst to convert the handwritten records to digital tables using pictures taken for each page of the record book as a reference for entering the data in Excel. Once the spatial GPS and attribute data are collected, it is convenient to combine them into a geodatabase in GIS, so exact locations and records related to gravesites could be accessed, mapped, and updated easily using the computer without having to page through paper maps and books manually. Cemetery managers can painlessly map the available gravesites and match them to the requests of their customers (Liebens, 2003).

The proposed statistical and generational analysis methods can be easily implemented to other studies of a similar manner, even though the demographics of cemeteries established elsewhere or at different times and sizes may reveal different statistics and demographic results presented by Woodland Hills. For cemetery managers, it is important to know how many plots are available for purchase for each garden in the cemetery and where they are located so they can push sales of the empty plots in specific locations and avoid single empty plots surrounded by filled ones. Such kind of questions can be easily answered using the digital geodatabase created in GIS. In addition to mapping the filled and empty gravesites, the database users can analyze the spatial patterns and demographical attributes efficiently as demonstrated in this case study. Likewise, information such as the differences between nonveteran and veteran groups in terms of their birth, death, and age distributions, as well as the ethnic background and generational information of the inhabitants will be beneficial to future historians or individuals interested in the local culture and history.

Moreover, the spatial analysis in GIS could efficiently identify spatial characteristics and patterns (clustered, dispersed, or random) existing in the data and provide implications for future cemetery management. For example, the clustered patterns of the Generation categories identified in Woodland Hills suggest that individuals desire to be buried next to other of the same age group, whether out of practical necessity or out of preference for the familiar. In addition, the clustered pattern may also be attributed to the fact that couples, usually from the same generation, are traditionally buried next to each other. Therefore, gravesites that lack other empty plots surrounding them will be harder to sell than those with spaces surrounding them. While Woodland Hills sells all of their grave plots at the same rate, other cemeteries may take advantage of such practices of putting more value on filling up areas. Finally, the cemetery data layers created in the GIS framework can be easily exported to Keyhole Markup Language (KML) files that can be viewed in the open-source Google Earth, which provides an alternative option for sharing data with individuals unfamiliar with GIS software.

However, the geodatabase, GIS and KML data layers, and other products created in this study are only accessible in local computers. If more budget and time allow, it would be ideal to make the data available through a webbased mapping service, like the ANC Explorer in Arlington National Cemetery, to host and store the cemetery data on the Internet. This will enable families and visitors to search for gravesites online. Along with web maps, web applications that provide an image of the gravesite and directions to a specific grave could also be created, which would make it possible to provide users with virtual tours of the gravesite. In addition, highly accurate topographic data could be collected in the field with a combined technology of Light Detection and Ranging (LiDAR) and Unmanned Aerial Vehicle (UAV) sensing to provide a better understanding of the layout of the cemetery. Groundpenetrating radar (GPR) can help determine whether the vacant graves are truly unused, or to find gravesites that may have been incorrectly marked. Lastly, for more reliable demographic and genealogical analysis, adding more cemeteries or additional demographic attributes (e.g. ethnicity and family ties) to the geodatabases would be helpful. 


\section{Conclusion}

One major purpose of this research was to explore how geospatial technologies could be used to transform localscale cemetery records into a digital geodatabase with limited time and budget. It was found that a high locational accuracy could be achieved based on carefully designed GPS data collection strategies. The geodatabase that links the GPS data and attributes of the gravesites in GIS could greatly facilitate data query and cemetery management. Another goal of this study was to conduct gravesites inventory for Woodland Hills and demonstrate how we could analyze the spatial and attribute data of the cemetery using the geodatabase. It was proven that the data can be easily queried, the spatial patterns can be visually mapped, and the demographic analysis can be efficiently conducted.

In conclusion, this research provides a template for other projects of a similar manner and contributes to improving cemetery management with digital methods of collecting, storing, processing, and analyzing data. In addition, the geodatabase, accurate spatial maps, methods, and analysis results created in this case study would not only enable the managers of Woodland Hills to better manage the cemetery in a cost and time-saving way but also allow the users and researchers efficient access to relevant information. The proposed procedure and methods can be easily applied in other local-scale study sites. If more budget and time allow, this project can be further developed by the creation of web maps and applications and the uses of LiDAR, UAV, and GPR technologies.

\section{Acknowledgments}

This research was funded by a Faculty Research Grant (2017-2018) of the Minnesota State University, Mankato. We thank the cemetery manager of the Woodland Hills Memorial Park Cemetery, Michael Brenna, for his support through the project. We thank Adelaide Schmidt and Kayla Christiansen for their assistance in the GPS data collection. We would also like to extend our gratitude to Dr. Sudarshana Bordoloi for proofreading the manuscript.

\section{References}

Ayers, B. (2006). Requiem: the medieval monastic cemetery in Britain. By Roberta Gilchrist and Barney Sloane. Archaeological Journal, 163, 284-285, https://doi.org/10.1080/00665983.2006.11020690

Basmajian, C., \& Coutts, C. (2010). Planning for the disposal of the dead. Journal of the American Planning Association, 76, 305-317, https://doi.org/10.1080/01944361003791913

Bennett, G., \& Davies, P. J. (2015). Urban cemeteries planning and the conflicting role of local and regional interests. Land Use Policy, 42, 450-459. https://doi.org/10.1016/j.landusepol.2014.08.011

Coutts, C., Basmajian, C., \& Chapin T. (2011). Projecting landscapes of death. Landscape and Urban Planning, 102, 254-261. https://doi.org/10.1016/j.landurbplan.2011.05.005

Davies, P. J., \& Bennett, G. (2016). Planning, provision and perpetuity of deathscapes-past and future trends and the impact for city planners. Land Use Policy, 55, 98-107. https://doi.org/10.1016/j.landusepol.2016.03.029

El-Rabbany, A. (2006). Introduction to GPS-the Global Positioning System, 2nd ed.; Artech House, Inc., USA

Faye, B., \& Channac, F. (2017). A hedonic approach to burial plot value in French cemeteries. Urban Studies, 54, 2835-2855. https://doi.org/10.1177/0042098016655036.

Gonzalez-Tennant, E. (2009). Using geodatabases to generate "living documents" for Archaeology: a case Study from the Otago Goldfields, New Zealand. Historical Archaeology, 43, 20-37. https://doi.org/10.1007/BF03376758

Grimes, J. (n.d.) Global Positioning System, standard positioning service, performance standard. https://www.gps.gov/technical/ps/2008-SPS-performance-standard.pdf

Güney, C., Celik, R. N. (2003). Multimedia supported GIS application for the documentation of historical structures. Survey Review, 37, 66-83. https://doi.org/10.1179/sre.2003.37.287.66

Hussein, I., \& Rugg, J. (2003). Managing London's dead: a case of strategic policy failure. Mortality, 8, 209-221. https://doi.org/10.1080/1357627031000087433

Johnson, P. (2008). The modern cemetery: a design for life. Social \& Cultural Geography, 9, 777-790. https://doi.org/10.1080/14649360802383154 
Kim, J., Song, J., No, H., Han, D., Kim, D., Park, B., \& Kee, C. (2017). Accuracy improvement of DGPS for low-cost single-frequency receiver using modified Flächen Korrektur parameter correction, International Journal of Geo-Information, 67, 222. https://doi.org/10.3390/ijgi6070222

Lee, J., \& Li, S. (2017). Extending Moran's Index for measuring spatiotemporal clustering of geographic events. Geographical Analysis, 49, 36-57.

Lejeune, S., \& Warnant, R. (2008). A novel method for the quantitative assessment of the ionosphere effect on high accuracy GNSS applications, which require ambiguity resolution. Journal of Atmospheric and SolarTerrestrial Physics, 70, 889-900. https://doi.org/10.1016/j.jastp.2007.01.009

Li, X., Ge, M., Dai, X., Red, X., Fritsche, M., Wickert, J., \& Schuh, H. (2015). Accuracy and reliability of multiGNSS real-time precise positioning: GPS, GLONASS, BeiDou, and Galileo. Journal of Geodesy, 89, 607635. https://doi.org/10.1007/s00190-015-0802-8

Liebens, J. (2003). Map and database construction for an historic cemetery: methods and applications. Historical Archaeology, 37, 56-68. https://doi.org/10.1007/BF03376623

Lilliefors, H. W. (1967). On the Kolmogorov-Smirnov Test for normality with mean and variance unknown. Journal of the American Statistical Association, 62(318), 399402. https://doi.org/10.1080/01621459.1967.10482916

Longoria, T. (2014). Are we all equal at death?: death competence in municipal cemetery management. Death Studies, 38, 355-364. https://doi.org/10.1080/07481187.2013.766655

Mann, H. B., \& Whitney, D. R. (1947). On a Test of whether one of two random variables is stochastically larger than the other. Annals of Mathematical Statistics, 18(1), 50-60. doi:10.1214/aoms/1177730491.

Marathe, T., Daneshmand, S., \& Lachapelle, G. (2016). Assessment of measurement distortions in GNSS antenna array space-time processing, International Journal of Antennas and Propagation, 2016, Article ID 2154763, 17 pages, https://doi.org/10.1155/2016/2154763

Martinez, J. L., Martinez, M. A., \& Garcia-Cerezo, A. (2000). A new method of generating differential GPS corrections. Control Engineering Practices, 8, 253-258. https://doi.org/10.1016/S0967-0661(99)00158-6

Matero, F.G., \& Peters, J. (2003). Survey methodology for the preservation of historic burial grounds and cemeteries. APT Bulletin: The Journal of Preservation Technology, 34, 37-45.

Montalbano, E. (2012). Historic Arlington Cemetery Gets Digital Makeover. http://www.informationweek.com/software/information-management/historic-arlington-cemetery-getsdigital-makeover/d/d-id/1103304

National Park Service (NPS) (n.d.). Cultural resources GIS: mapping history for the future. https://www.nps.gov/crgis/

Nielsen, C. F., Kidd, S., Sillah, A. R., Davis, E., Mermin, J., \& Kilmarx, P.H. (2015). Improving burial practices and cemetery management during an Ebola virus disease epidemic - Sierra Leone, 2014. Morbidity and Mortality Weekly Report, 64, 20-27.

Paine, C. (1992). Landscape management of abandoned cemeteries in Ontario. APT Bulletin: The Journal of Preservation Technology, 24, 59-68.

Pattison, W. D. (1955). The cemeteries of Chicago: a phase of land utilization. Annals of the Association of American Geographers, 45, 245-253.

Quesada, F., Baena, J., \& Blasco, C. (1994). An application of GIS to intra-site spatial analysis: the Iberian Iron Age cemetery at El Cigarralejo (Murcia, Spain). Computer Applications and Quantitative Methods in Archaeology, 600, 137-146. 
Razali, N., \& Wah, Y. B. (2011). Power comparisons of Shapiro-Wilk, Kolmogorov-Smirnov, Lilliefors and Anderson-Darling tests. Journal of Statistical Modeling and Analytics, 2, 21-33.

Rugg, J. (2000). Defining the place of burial: What makes a cemetery a cemetery? Mortality, 5, 259-275. https://doi.org/10.1080/713686011.

Sanjuán, L. G., \& Wheatley, D. W. (1999). The state of the Arc: differential rates of adoption of GIS for European heritage management. European Journal of Archaeology, 2, 201-228. https://doi.org/10.1179/eja.1999.2.2.201

Schmidt, M. L. (2018). Cemetery management in a GIS framework: a case study of Woodland Hills Memorial Park, an alternative plan paper submitted in partial fulfillment of the requirements for the degree of Masters of Science in Geography, Minnesota State University, Mankato, Minnesota, USA

Scholz, M. (2017). Over our dead bodies: the fight over cemetery construction in nineteenth-century London. Journal of Urban History, 43, 445-457, https://doi.org/10.1177/0096144215584152

Shapiro, S. S., \& Wilk, M. B. (1965). An analysis of variance test for normality (complete samples). Biometrika, 52, 591-611. https://doi.org/10.1093/biomet/52.3-4.591

Shular, M. D. (2009). Turning Genealogists onto GIS. Journal of Map \& Geography Libraries, 5, 55-71. https://doi.org/10.1080/15420350802508134

Skår, M., Nordh, H., \& Swensen, G. (2018). Green urban cemeteries: more than just parks. Journal of Urbanism: International Research on Placemaking and Urban Sustainability, 11, 362-382. https://doi.org/ 10.1080/17549175.2018.1470104

SPSS (n.d.) SPSS Shapiro-Wilk Test - Quick Tutorial with Example. Available online: https://www.spsstutorials.com/spss-shapiro-wilk-test-for-normality/

Spurgeon, I. M. (2017). The fallen of operation iceberg: U.S. graves registration efforts and the battle of Okinawa. Army History, 102, 6-21.

Stein, J. (2006). GIS tools for cemetery management. https://www.nps.gov/crgis/proj_alexandria_cemetery.pdf

Swensen, G., Nordh, H., \& Brendalsmo, J. (2016). A green space between life and death - a case study of activities in Gamlebyen Cemetery in Oslo, Norway, Norsk Geografisk Tidsskrift - Norwegian Journal of Geography, 70, 41- 53. https://doi.org/10.1080/00291951.2015.1102169

Weng, D., Ji, S., Chen, W., \& Liu, Z. (2014). Assessment and mitigation of ionospheric disturbance effects on GPS and integrity. Journal of Navigation, 67, 371-384. https://doi.org/10.1017/S0373463314000046

Wong, D. W. S., \& Lee, J. (2005). Statistical Analysis of Geographic Information with ArcView GIS and ArcGIS, John Wiley \& Sons, Inc. Hoboken, New Jersey, USA.

Woodthorpe, K. (2011). Sustaining the contemporary cemetery: implementing policy alongside conflicting perspectives and purpose. Mortality, 16, 259-276. https://doi.org/10.1080/13576275.2011.586125.

\section{Copyrights}

Copyright for this article is retained by the author(s), with first publication rights granted to the journal.

This is an open-access article distributed under the terms and conditions of the Creative Commons Attribution license (http://creativecommons.org/licenses/by/4.0/). 